\title{
Chance as an existential reality: on one of the most fundamental categories in Alexander Herzen's thought
}

\author{
Jacek Uglik ${ }^{1}$ \\ Published online: 12 November 2019 \\ (c) The Author(s) 2019
}

\begin{abstract}
The article emphasises that the importance of Herzen's philosophical input is related to his human-centered approach. There are three areas of investigation that are of particular importance in this context: responsibility, freedom and chance. I argue that according to Herzen, chance, by tearing apart the net of supposedly necessary causes and effects in the physico-social world, proves that the existence of man is best understood as a manifestation of man's free agency. Whereas the lack of freedom would mean that an individual is as determined as the objects that surround him, and consequently, that he cannot be held accountable for his deeds.
\end{abstract}

Keywords A. Herzen · Russian philosophy · Human being · Chance

A central focus of all the philosophical ideas put forward by Alexander Herzen (1812-1870) are the issues related to the existence of an individual. The Russian thinker underscores that "human individuality is not something closed, it contains broad doors allowing for exit" (Herzen 1965, p. 415). Owing to this and similar statements, one can describe Herzen's work as an example of an open philosophy: as long as the world exists and man continues to interpret the reality that surrounds him, the story of the world remains open-ended. ${ }^{1}$ Each philosophical proposal thus becomes simply an element of a discursive quest, an act of an individual striving to define oneself in the physical, social and cultural dimensions of an ever-changing reality. As long as the world exists, our understanding of it is never final. This forms the backbone of Herzen's version of open philosophy (with the world viewed as a potentiality) championing a permanently critical approach and a rejection of

\footnotetext{
${ }^{1}$ In this spirit, Aileen Kelly says that Herzen "refused to prescribe his ideal as a final solution to social problems, on the grounds that a search for such a solution was incompatible with respect for human liberty" (Kelly 1994, p. XIX).
}

Jacek Uglik

j.uglik@ifil.uz.zgora.pl

1 Institute of Philosophy, University of Zielona Gora, al. Wojska Polskiego 71A,

65-762 Zielona Gora, Poland 
all time-honoured narratives in our quest to understand the world. ${ }^{2}$ Eventually, the analysis of the practical aspects of philosophy leads Herzen to stress the importance of contingency. This aspect of his philosophy was pointed out by Isaiah Berlin, who viewed Herzen-according to Andrzej Walicki- "as an existentialist philosopher dealing with the contingency of life, considered as a pre-requisite of freedom" (Walicki 2008, pp. 19-20).

For Herzen, man can find fulfilment only in the context of immanence (that is in the material world). This means that he is a mortal, or a temporal, being, hence an accidental substance: a temporal character of a being is always associated with its accidental character (Herbut 1997, p. 456). Importantly, it is freedom, or rather the pursuit of freedom, devoid of any transcendental justification, that is the content of the existence as defined above. In justifying this view, Herzen notes that all substance known from experience, including an individual man, has an accidental character and thus cannot warrant the existence of any necessary, final and infinite substance. Herzen emphasises that in accepting the existence of the final and necessary being, there lurks a danger of viewing all contingent beings as mere tools in the hands of this supreme being. Hence, when speaking of existence, he avoided the problem of potential tensions between immanence and transcendence by narrowing all reality to immanence, accidentality (contingency), to the realm of errors and partial truths.

Thus, the reality described in such a way, which includes both nature and nurture, rejects universal purposefulness. It does allow, however, the notion of necessity to become a meaningful part of the discourse on the world, especially in the context of past events. The guiding principle is as follows: what happened, must have happened. Note that this does not mean that there is only one, all-encompasing, vision of the past. Herzen emphasises that the perception of reality is always selective, meaning that one is faced with a multitude of stories describing the past. As a result, one is able to distinguish among, say, political history, the history of literature (and, as its subsets, the histories of various national literatures) or the history of art. Each thread of this kind belonging to the past is, in a sense, a story in its own right. For him therefore, a deeper analysis of the past reveals its multifarious character. The notion of necessity appears also in the context of existential concreteness-a child will, discounting the accidentals occurring during its development, turn into an adult, which is still necessarily defined by the notion of a "man". It will not turn into a non-man. Nevertheless, the fact that a man as a child has blond hair and as an adult his hair darkens is merely an accidental circumstance. The existential necessity, viewed as a part of the reality as defined above, does not exclude an accidental event, which, it should be stressed, has a similar existential status. We know for example that Earth attracts an object thrown into the air. This much for the theory. We do not know, however, either in which way it is going to fall or where or on

\footnotetext{
${ }^{2}$ Note that such-conceived open philosophy anticipates the ideas of later philosophers e.g. Friedrich Nietzsche or Jean-Paul Sartre. All such philosophers reacted against the view of the world as a rigid, closed structure, ejecting the philosophical interpretation of the world presented as a system or a schema. As such, they can, each in their own way, also be considered proponents of open philosophy.
} 
which side it is going to land, or even whether it is going to fall down at all: it is probable that it will, for example, get stuck on a tree-thus we are faced with the practical side of the problem, dependent on a number of causes.

It is worth pointing out that right before his death, Herzen spoke of "a development of freedom into necessity", which bears on the problem I am discussing here (Herzen 1966, p. 746). From the above I conclude that the phenomenal world is subject to determinism, but that all phenomena also have an accidental aspect. A fact, or the occurring phenomenon (using the language that, through Alexey Khomyakov, can be traced directly to Hegel), is being divided into its logical and real aspects. In Herzen's opinion, Khomyakov claimed that

a logical fact cannot contain full knowledge of a real fact for the following reason. One side of a fact is accidental, and the thought abstracts from it; Hegel accepts yet abandons it, focusing on what is necessary; ... and abandoning chance is possible in theory but not in practice .... A man in the embryonic state has to develop into a mature individual, necessity lies in the notion of an embryo, yet an accident cuts the thread of life and the fact does not materialise. Therefore, chance is important for a fact, yet it is the thought that considered it to be unimportant (Herzen 1966, pp. 655-656).

In my opinion, the writings of Herzen (especially those dating from the late period of his life) show that his own ideas were, in fact, close to what he stated about Khomyakov. A thought - therefore also a notion, definition, reason and, as a result, the entirety of science - all ignore the reality of the existence of a particular man (an accidental substance). Despite the fact that the development of each individual is necessarily determined by the initial conditions, the focus on contingency shows us that this necessity is grounded in possibility - the specific human being, which while it cannot transform into a non-man, does not have to reach the level of maturity and reach the level of a fully-grown person. Let me add that any accidental event is also determined, as it has its cause, which is, however, entangled in a web of still other causes. Hence Herzen would say that "the entire individual side of man is entangled in a dark labyrinth of chance events that cross and intertwine ... forming a concordant whole or a dissonant ensemble" (Herzen 1965, p. 415). Despite the fact that all accidental events have their causes, one is not able to analyse it beforehand and therefore to predict the events that are to take place. We take into account that accidental events do happen, that it truly is a part of our existence and that it is strongly connected to the notion of freedom-which, from Herzen's point of view, is the most important factor. Only a man viewing himself as a free being is able to go beyond the framework of a non-conscious phenomenon occurring in nature and history "as without this belief, individuality falls apart in the darkness of chaos" (Yakovenko 2003, p. 102; see also: Malia 2010, p. 510; Kelly 1980, p. 635).

I believe that individual freedom, as Herzen understood it, can be viewed as consisting of the following three elements: (a) a decision, which is accompanied by a related factor, emphasising its importance, namely (b) responsibility; and finally a factor that can never be fully controlled by the decision-making agent, that is (c) chance. The last component, chance, is also present in the world outside of free 
choice. It is important to emphasise that the category of chance had not played any important role in Herzen's writings until 1830s, when he experienced a series of devastating blows caused by blind forces operating in the world when some of his children passed away. ${ }^{3}$ Let me add that combining a necessary choice with freedom does not lead to a paradox, since freedom by definition is connected to some sort of a limitation, in this case manifesting itself as a responsible decision. The lack of a limitation would indicate not freedom but wilfulness, which is destructive for morality and is thus rejected by Herzen.

As Herzen saw it, the necessity of making decisions not founded on clues, that provide one with certainty and the necessity of succumbing to the stream of chance events, lead those with a tendency to sentimentalism to invent pessimistic scenarios about the nature of reality. He says that such people are unable to "recall without tears that people are born only to die" (Herzen 1965, p. 540). Note that Herzen's own approach could not be further away from what can be described as anthropological pessimism, it is not to say, however, that he is indifferent to human tragedies that do take place. ${ }^{4}$ A chance event is absurd but it is part of the world, a part of what we call the existential reality, against which one cannot rebel. This notion also encompasses each contingent and free Ego. An individual man exists and acts as a conscious and contingent phenomenon, lost in the multitude of possibilities and, importantly, not introduced into the world of nature and culture in any sort of aimoriented or a planned manner. Without justification he appears and without justification he departs. He is surrounded by nothingness. It is worth noting that Herzen clearly emphasises the importance of a particular being (in the existence of which chance plays an important role), rather than man in general, thus re-evaluating certain philosophical ideas, to which Hegel's name is often attached. The Russian thinker, paraphrasing Plekhanov, concludes that what is real is identical to what exists, that real existence is not necessary, and finally that each contingent existence is real (cf. Plekhanov 1967, p. 188). A particular real existence is not necessary in the sense that it is not an essential part of the world, which it nevertheless co-creates in one way or the other. An individual person "occurs" within clear boundaries of immanence (matter), appears out of nothingness and turns into nothingness, its presence being at the same time its sole justification for existence. The existence of

\footnotetext{
${ }^{3}$ In his letter to Ogarev from 1841 he writes: "How can one not grieve when before one's eyes matter battles with spirit, and spirit is vanquished and mindless forces gain ascendancy over life?" (Gertsen 1961b, p. 100). This theme is also taken up by Aileen Kelly in her The Discovery of Chance. The Life and Thought of Alexander Herzen, Cambridge-London 2016; see Chapter X entitled The Discovery of Chance (see also: Acton 2009, p. 10). Still, even in 1836 in his letter from Vyatka, when writing about love as a relation between man and God, Herzen jotted down the following statement about chance: "Nonsense, there's no such thing as Chance, that's an absurdity, invented by unbelief" (Gertsen 1961a, p. 118).

${ }^{4}$ One should note that such tragedies most likely influenced Herzen's thought in a more direct way. As mentioned before, between 1841 and 1864 Herzen lost some of his children. In 1851 r. his son Kolya together with Herzen's mother died in a shipwreck. A year later Natalie, Herzen's wife, died and in 1875 his seventeen-year-old daughter Liza commited suicide. Despite such ordeals, in our opinion, Herzen's philosophical propositions should not be classified as pessimistic-however there are researchers that would argue that this is the case. I shall get back to this later on in the article (see Kelly 2016, pp. 332335; Davison 1966, p. 193).
} 
chance does not destroy the order found in reality as, according to Herzen, chance co-creates both the past and the future (see Herzen 1965, p. 541). One cannot, therefore claim that reality is a rigid structure where all phenomena take place in a necessary manner. Herzen would have agreed, for example, with Holbach (whose ideas are often related to notions exemplifying the tension between necessity and chance), who claimed that the entirety of nature cannot have any aim. The reason being that outside of nature, there is nothing to which it could strive for. The parts themselves, however, do have some aim (see Holbach 1889, p. 37), e.g. an individual human being can set himself goals. Herzen would, however, most definitely have not agreed that 'chance' is a completely nonsensical word, as Holbach claimed (cf. Holbach 1889 , p. 37). For example, Holbach, reaching to the realm of physics, says that "In a whirlwind of dust, raised by the impetuous elements, confused as it appears to our eyes in the most frightful tempest, excited by contrary winds, when the waves roll high as mountains there is not a single particle of dust, or drop of water, that has been placed by chance; that has not a sufficient cause for occupying the place, where it is found that does not, in the most rigorous sense of the word, act after the manner in which it ought to act; that is, according to its own peculiar essence, and that of the beings from whom it receives impulse. A geometrician, who exactly knew the different energies acting in each case, with the properties of the particles moved, could demonstrate that after the causes given, each particle acted precisely as it ought to act, and that it could not have acted otherwise than it did" (Holbach 1889, p. 31). The above analysis, however, would have been rejected by Herzen. One could argue that chance occurrences are indeed possible, contrary to what Holbach claimed. For Herzen, the idea of reduced certainty in the context of the vortex of dust could make sense when the forces involved are well-known, hence predominantly in the case of past events. However, the day-to-day existence is related to the existence where one cannot clearly delimit the initial conditions. And it is for that reason that Herzen calls life a vortex of chance events. I would like to stress that his approach is equally "justified" as the argument made by Holbach: chance and freedom for Herzen, and necessity and determinism for Holbach can both be described as parts of the existential reality. In this context, it is worth pointing out that Herzen's Letter on Free Will ends with the following phrase: "man has to feel free" (Herzen 1966, p. 746). An additional difference between the Russian thinker and Holbach lies in the fact that the former does not consider his views in a dogmatic manner. For him, one cannot accept determinism understood as the theory stating that a given cause necessarily brings forth a given effect, since such a relation is merely probable. This does not mean that a chance event does not have a cause, however. On the contrary-it is an indefinite, unnoticed cause, which brings as a result an unpredictable effect, but a cause nevertheless. A chance event and the cause-effect relation connected to it are a potentiality, merely a possibility, that we treat as the reality since it does occur. For Herzen, this belongs to nurture as opposed to nature. ${ }^{5}$ A notion of chance

\footnotetext{
${ }^{5}$ In his Letter on Free Will, addressed to his son Alexander, Herzen emphasises: "Undoubtedly, by generalizing, simplifying and reducing facts to their simplest expression, we shall ultimately arrive at motion, and perhaps, that will be true; but we lose the world of phenomena, full of diversity, quality and details a world in which we live and which alone is real" (Herzen 1966, p. 743).
} 
fits well into the idea of open philosophy-open to mutation, variation, probability, impermanence and to a selective view of reality, which is co-created by man. Necessity, purposefulness and permanence of the world viewed as a composition with an unchanging structure, where strict determinism rules everything "would rid us of free will and change us into cogs in the wheel" (Kelly 1991, pp. 400-401). ${ }^{6}$ An occurrence of a chance event, therefore, is to prove the existence of freedom, since this tear apart the net of a seemingly necessary series of causes and effects. Chance events appear in a way that interferes with all predictions. Moreover, man is not only a body viewed as a part of nature but - as the creator of culture and history-also the existential reality beyond the natural world. Herzen observes that "nothing is absolutely necessary. The future is never irreversibly fixed: it has no unchangeable predestination. There might be no future at all" (Herzen 1966, p. 263). In the existential plane, the chain of causes and effects does not have a necessary character, and hence, we would say that good intention merely has a potential to be transformed into a good effect.

A chance event, by definition an unexpected situation, cannot be an object of scientific studies. A flowing existence cannot be analysed, if we accept that it is "merely a blind game of chance, eternal improvisation that never repeats itself" (Walicki 1995 , p. 61). ${ }^{7}$ The picture of the world is not, however, created only by science (the main tool of which is reason). In science, what will be is predicted on the basis of what has already happened. In an extreme interpretation: it is predicted "with necessity". For Herzen, putting things this way seems naive. Existence is much broader; even when identifying its necessary essence, we ignore the outskirts, things that are not easily graspable by reason and science. Thus, it can at most say something about a man in general and not about an individual subjective experience, "man in general" is not a real, but a theoretical, being, and it is a construction. Reality is identified by Herzen with the state of concreteness. It is identified with a free individual (a part of a network of causes and effects), who by making a choice yearns to determine the shape of the reality, whose decisions become the causes of certain effects. A man, however, "viewed as an individual having a corporeal and a spiritual structure, ... is not fully determined by external factors, as auto-determinism is built into his structure" (Mazierski and Zięba 1997, p. 112). Man breaks causality as a being endowed with the ability to choose, a being which is always contingent, and is

\footnotetext{
${ }^{6}$ Narcyz Łubnicki discussing the practical side of Herzen's ideas notes that "it might well be that the realisation about the freedom of one's actions and the belief in the existence of the external world is just a delusion but 'without this belief man would not have been able to make a single step'. In other words, the practical needs of human life, constant activity forces man to assume realism and indeterminism as the foundations of his actions" (Łubnicki 1973, pp. 516-517).

7 Elsewhere, Walicki writes that "emphasising the role of chance (...) was motivated by (...) the wish to create a philosophy of history that leaves more space to free choice and provides a more meaningful role to be played by a conscious will" (Walicki 1966, p. XXV). According to Herzen, "the future does not exist, it is created by a multitude of conditions, both necessary and accidental and free human will that introduces unexpected dramatical solutions and coups de théâtre. History is an improvisation, it seldom repeats itself, it makes use of every opportunity, knocking at a thousand doors at the same time" (Herzen 1965, p. 541). Martin Malia emphasises that according to Herzen, the key role in terms of shaping the future was played by active individuals (Malia 2010, p. 509).
} 
thrown into the world without justification. This means that man introduces an unexpected cause into the established series of causes and effects. Herzen illustrates this intuition in the following way:

Being a product of physiological and historical necessity, the individual strives to confirm his being between the two non-beings of his existence-non-being before birth and non-being after death. Developing under the laws of this fateful necessity, he invariably regards himself free on this path. That is the essential condition for his activity, it is a psychological and social fact (Herzen 1966, p. 745).

According to Herzen, in the world of immanence, only the egoists (cf. Herzen 1966, p. 692) can feel comfortable. For Herzen, however, egoism cannot be the feature of bona fide individuals: the idea of personality is tied to the notion of responsibility (which is in turn determined by man having free will). Man, that would have been determined in a way similar to objects, could never have been held responsible for his deeds. Herzen, therefore, assumes the existence of freedom that leaves a room for chance in the form of the accidental character of human beings. ${ }^{8}$ An "occurring" man, that is a contingent being, is precisely such a chance occurrence, a combination of events of quite a mundane character.

The awareness of the existence of chance does not lead Herzen to despair, as it was the case with e.g. Voltaire, who famously complained that it is hard to understand why the laws of motion have to lead to such havocs in this "the best of all worlds" (see e.g. Derzhavin 1962, p. 202). This pessimistic approach also shines through P. Novgorodtsev's analysis of From the Other Shore where chance is combined with relativism and the lack of meaning (cf. Walicki 1995, p. 343). Herzen, however, does not approve of relativism, and the lack of universal meaning in the world does not exclude, he believes, the existence of subjective meaning, or meanings of a number of subjectivities. He says that a responsible and self-aware man is able to save something individual from the whirlwind of chance events (Herzen 1965, p. 476). A man, therefore, is not condemned to an emotional and moral void, his task as a person is to tame the reality where the reference points (cultures, religions) do not have a constant character and instead are changeable, variable in space and time, and precarious. Or to put it differently: only the vortex of chances is for Herzen something that is constant and unchangeable. The reality of immanencethe perishable world, where chaotic behaviour takes place-is contingent, and contingency can be viewed also as an infinite possibility. In other words, it is an openness. The nature of the immanent reality as described by Herzen is changeable. And such a change is always connected to inquietude, transience and death, thus when faced with contingency, it is pointless to talk about a "universal peace" (Herzen

\footnotetext{
${ }^{8}$ Here, we encounter an argument similar to the one made by Michał Heller, who believes that "the existence of chance events in the structure of the Universe is something indisputable. Chance events are not something exceptional. The structure of the Universe is interspersed with chance events" (Heller 2011, pp. 11-12). Heller, however, who extends reality to the transcendent sphere, differs markedly from Herzen.
} 
1966, p. 692). It is the contingency of the world that makes it beautiful, there is no use wasting time talking about probabilities, if the reality is connected to actioninspiring self-aware concreteness (an individual that is contingently present in space and time). The Russian thinker would say that openness is a feature of "an awareness of one's own individuality" (Herzen 1965, p. 497). It is evident that the contingency of the world is something that is embraced by him, the contingency from which all the individual beings try to escape-the "occurring" contingent being is, however, irrational, probable but not predictable. Man prefers to tame the reality by assuming that a chance event is in fact a part of a detailed plan,

he prefers to make believe in bad luck and succumb to it; he wants the calamities that fall upon him to be pre-determined, and hence related to the general order; he wishes to view disasters as persecutions, as punishments: this allows him to seek consolation in either submissiveness or rebellion (Herzen 1965, pp. 415-416)

Herzen's ideas only allow a narrative that is bounded by immanence, there is no creator who would "intersperse" reality with chance events that are aberrations from the assumed tendency. It is naive to think that reference points one notices in the world are unchangeable, as these are fluid and can fall apart, and man's expectations, his revolt and despair, cannot change this. Herzen, when describing contingency as an important element, recalls the words of Goethe that "beauty fades away, since only what fades can be beautiful-and humans consider this an injustice" (Herzen 1965, p. 542). An individual being formed into a specific shape with no guarantee for either happiness of future is also something viewed as real.

An analysis of Herzen's theoretical constructions can be made easier by looking at what Barbara Skarga had to say on related topics. In her Tożsamość i różnica [Identity and Difference], Skarga compares the two categories. She notes that with regard to identity,

Leibniz wrote that it is ... a principle innate to the human mind, a principle that makes human knowledge possible. Since in order to know something, one has to be able to identify the object to which the knowledge is to be applied, as we need to be certain that it is the knowledge of the one thing we are interested in and not of the other. ... Besides, knowledge cannot exist without concepts .... We look for identity everywhere: in things, relations, events, and it is on this basis that we determine scientific laws identical for all places and times (Skarga 1997, p. 11).

The need for identity seems to be something obvious, since man wishes to co-create the world and "to make it his own"; the world, which is in a sense personal, and in this way, similar to, say, topographical knowledge. The converse, which is also a negative side of this wish, is the attrition of individuality as one identifies and classifies oneself not in a reference to a chosen specific Ego but to a specifically defined class of universals - thus making one into, at most, a representative of a given group, nation or species. The identified individual is incorporated into some community. Classifying, we therefore search for common features, qualities allowing 
one to differentiate among a mass of beings. This is the way in which science works, science that is founded on reason and makes use of concepts, that systematizes and generalizes, and thus, does not speak about an individual Ego. For science, Ego exists only as a part of a larger whole: "a concept abstracts away all that is different, individual, personal, accidental” (Skarga 1997, p. 11). Thus we are once again back to Herzen's characterisation of the immanent reality. The point of view of science, as exemplified by the exact sciences, is not the only one. I have mentioned that for Herzen the material world contains two existential levels - that of nature and that of culture (history): it follows that science, which uses concepts and is founded on reason, describes being not in its, arguably complicated, entirety but only partially. In the area of broadly-conceived culture, there exist other sources of knowledge, such as intuition, faith or internal experiences. Let us also emphasise that Herzen's materialism does not negate the spiritual sphere. ${ }^{9}$ By emphasising the importance of such internal experiences in human knowledge, Herzen "rehabilitates" chance and singularity. Both of these elements escape science, since they are hard to put into categories. From the point of view of science (symbolised by the category of identity) "that, which is singular, individual does not have any meaning" (Skarga 1997, p. 12). For Herzen, however, all this marginalised space of contingency and exceptions is the "prime reality". Categorising the scattered reality in terms of reason and language does not automatically make it orderly. Naming does not change reality but merely alters the view of the one who is assigning the names and uses the language. From Herzen's point of view, all attempts at permanent taming of the world, which to him is a vortex of chances and a constant improvisation, are doomed. In his analysis, he emphasises intimacy, the difference that makes man a unique being, rather than viewing man as merely a part of a greater whole: "Throughout the ages man has sought to find his autonomy, his freedom, and, influenced by necessity, does not want to do anything other than what he desires" (Herzen 1966, p. 745). ${ }^{10}$ Thus, we can call the Russian thinker, a "philosopher of the difference". He was horrified by the thought that

the world has been ordered once and for all, ... that all the disturbances at the edges of the observed phenomena are only of marginal importance .... Is it not horrifying to hear that there is only one order of the world and it will last forever .... Does this pursuit not contain the threat of unification of various areas of life and human activity, subjecting them to schematic rules? (Skarga 1997, pp. 12-13).

An emphasis on differences and subjectivity fits well in terms of scope and meaning into the anti-schematic approach of what I called an open philosophy, which

\footnotetext{
9 Kazimierz Ajdukiewicz presents this in the following way: "we seem to believe that by viewing ourselves and others as mere bodies we loose our dignity .... Materialism does not go against everything that is noble and virtuous. ... It does not contradict the existence of our mental life .... It does, however, rid us of the belief in afterlife. Here, for many, lies the tragedy of this doctrine that is at the core of its rejection" (Ajdukiewicz 1983, p. 157).

10 This theme has been also picked up by Acton, who says that man has an egoistic tendency to give meaning to some part of reality. See Acton (2009, p. 18).
} 
is oriented towards the dailiness. This dailiness, pulsating with life, entwines the contingent individual in a net of social relations, where chance also plays a role. Despite the fact that a single human being is a chance event of a marginal, ontologically speaking, character-and according to Herzen this is precisely the case-such an individual is still axiologically important. Therefore, when describing the meaning of chance in Herzen's works, we treat an individual as a value projecting itself towards either affirmation or degradation. Skarga, indirectly touching upon Herzen's philosophical intuitions, wonders whether the fluid (open) being described in the categories of difference, chance, singularity that goes against "the identity in all its dimensions ... does hide a seed of disintegration and chaos; can it build ethics or, on the contrary, is capable of destroying it?" (Skarga 1997, p. 159). It seems that the acceptance of chance in the areas of nature and nurture is a price we pay for our own realness, allowing us to reject the vision of a perfectly tailored and designed reality, where man would stop being a person and became a puppet, an unimportant element of a big mechanism.

Herzen wanted to look at the world from the point of view of existential singularity, from the point of view of a responsible human being that keeps trying to construct ethics. And this seemed an important task as the edifice of ethics, as Herzen saw it, had visible cracks. It is not, and never will be a perfect building, since the world is permanently being created and men keep making mistakes. The ideal ethics can, however, be created in relation to the mentioned category of identity — or, using the language of Herzen: the category of universality. The creation of such a theoretical edifice comes at the price of stifling the individuality of a man. An individual is reduced to the role of an object, its existential content, expressed by individual happiness or sadness. As an unimportant part of a bigger whole, it is replaced by another element - not unlike a broken part of an engine. The dominance of the category of identification, understood as the necessity to subdue individuality, is realised in the ideas of totalitarian character, including these that are not openly threatening - such as the Platonic idea of a republic. Why, when being acquainted with the rules of the "perfect" Platonic republic, are we not inclined to help in its creation? The answer, in the spirit of Herzen, is as follows: because in this "ideal" construction there is no place for freedom and chance, which constitute personality.

Funding This publication was generously supported by a grant from the National Science Center, Poland, No. DEC-2013/09/B/HS1/00431.

\section{Compliance with ethical standards}

Conflict of interest The authors declare that they have no conflict of interest.

Open Access This article is distributed under the terms of the Creative Commons Attribution 4.0 International License (http://creativecommons.org/licenses/by/4.0/), which permits unrestricted use, distribution, and reproduction in any medium, provided you give appropriate credit to the original author(s) and the source, provide a link to the Creative Commons license, and indicate if changes were made. 


\section{References}

Acton, E. (2009). Alexander Herzen and the role of the intellectual revolutionary. Cambridge.

Ajdukiewicz, K. (1983). Zagadnienia i kierunki filozofii. Warsaw.

Davison, R. M. (1966). Herzen and Kierkegaard. Slavic Review, 2, 191-209.

Derzhavin, K. (1962). Wolter (W. Bieńkowska, Trans.). Warsaw.

Heller, M. (2011). Filozofia przypadku. Kosmiczna fuga z preludium i coda. Cracow.

Herbut, J. (1997). Przypadtość. In idem (Ed.), Leksykon filozofii klasycznej. Lublin.

Herzen, A. (1965). Pisma filozoficzne (Vol. 1) (J. Walicka, Trans.). Warsaw.

Herzen, A. (1966). Pisma filozoficzne (Vol. 2) (W. Bieńkowska, Trans.). Warsaw.

Holbach, P. (1889). The system of nature (H. Robinson, Trans.). Boston.

Kelly, A. (1980). The destruction of idols: Alexander Herzen and Francis Bacon. Journal of the History of Ideas, 41(4), 635-662.

Kelly, A. (1991). Irony and Utopia in Herzen and Dostoevsky: "From the Other Shore" and "Diary of a Writer". The Russian Review, 4, 397-416.

Kelly, A. (1994). A complex vision. In I. Berlin (Ed.), Russian thinkers. London.

Kelly, A. (2016). The discovery of chance. The life and thought of Alexander Herzen. Cambridge, London.

Łubnicki, N. (1973). Światopoglady. Warsaw.

Mazierski, S., \& Zięba, S. (1997). Determinizm. In J. Herbut (Ed.), Leksykon filozofii klasycznej. Lublin.

Malia, M. (2010). Alexander Gertsen i proiskhozhdenie russkogo sotsializma. 1812-1855. (A. Pavlov and D. Uzlaner, trans.). Moscow.

Plekhanov, J. (1967). Historia rosyjskiej myśli społecznej (Vol. 3) (R. Hekker et al., Trans.). Warsaw.

Skarga, B. (1997). Tożsamość i różnica. Eseje metafizyczne. Cracow.

Walicki, A. (1966). Twórca rosyjskiego socjalizmu. In A. Herzen, Pisma filozoficzne (Vol. 2) (W. Bieńkowska, Trans.). Warsaw.

Walicki, A. (1995). Filozofia prawa rosyjskiego liberalizmu. Warsaw.

Walicki, A. (2008). Rosyjscy inspiratorzy koncepcji wolności Isaiaha Berlina. Studia Philosophica Wratislaviensia, 2, 9-40.

Gertsen, A. (1961a). Sobranie sochineny v 30-ti tomakh. Vol. 21. Moscow.

Gertsen, A. (1961b). Sobranie sochineny v 30-ti tomakh. Vol. 22. Moscow.

Yakovenko, B. (2003). Istoriya russkoy filosofii. Moscow.

Publisher's Note Springer Nature remains neutral with regard to jurisdictional claims in published maps and institutional affiliations. 